\title{
Methadone maintenance treatment and HIV risk-taking behaviour among injecting drug users in Berlin
}

\author{
Klaus Stark, Reinhold Müller, Ulrich Bienzle, Irene Guggenmoos-Holzmann
}

\begin{abstract}
Study objective - To determine whether methadone maintenance treatment (MMT) is effective in reducing the levels of HIV risk-taking behaviour (borrowing and lending of injection equipment, irregular condom use) among injecting drug users (IDUs), and to identify independent predictors of the borrowing of used syringes.

Design - Cross sectional study of IDUs in MMT and not in MMT, using standardised interviews for collection of sociodemographic and behavioural data, and laboratory tests for detecting HIV antibodies. Setting and participants - The 612 IDUs were recruited at different services for drug users such as treatment centres, walk in agencies, a hospital, and on the streets. Main results - Of all IDUs, $41 \%$ had borrowed and $34 \%$ had passed on used injection equipment in the previous six months. In univariate analysis, IDUs receiving MMT had injected less frequently and were significantly less likely to borrow and lend syringes. In logistic regression analysis, MMT was protective against the borrowing of syringes (adjusted odds ratio $0.36,95 \%$ confidence interval $0.2,0.8$ ), but not against syringe lending nor against sexual risk behaviour (ie, numbers of sex partners, lack of condom use). Important independent predictors of the borrowing of syringes were injecting drug use in prison, use of sedatives, and sex with another IDU in the previous six months.

Conclusions - MMT may play a significant role in reducing the levels of borrowing of syringes among IDUs. However, additional prevention measures are needed which should specifically address sexual risk behaviour and target subgroups of IDUs with high levels of needle sharing, such as IDUs who have been in prison and and those who are sedative users.
\end{abstract}

( $(\mathcal{F}$ Epidemiol Community Health 1996;50:534-537)

Injecting drug users (IDUs) are at high risk of acquiring infectious diseases such as HIV infection or viral hepatitis through needle sharing and sexual transmission..$^{1-4}$ In recent years, IDUs have substantially reduced their levels of needle sharing (ie, the borrowing and lending of used syringes and needles) in many communities. There is evidence that such behavioural changes may at least in part be due to intensive AIDS prevention measures which have been implemented in many places. ${ }^{5-9}$ It has been suggested that methadone maintenance treatment (MMT) may have a preventive effect against needle sharing. ${ }^{10-12}$ However, the results on the impact of MMT on risk reduction among IDUs are conflicting. There are studies which found reduced levels of needle sharing among clients of MMT programmes compared with IDUs who were not in treatment. ${ }^{10} 12$ Since the MMT subsamples in these studies were recruited only directly at the treatment centres this could have resulted in an over-representation of IDUs in MMT with low risk behaviour. No protective effect of methadone against needle sharing was found in a study from Amsterdam among clients of a "low threshold" MMT programme. ${ }^{13}$ No data are available on the issue whether MMT is protective against the lending of syringes, and little is known whether IDUs in MMT have lower levels of sexual risk behaviour (ie, lower numbers of sex partners, increased levels of condom use). ${ }^{1114}$

In Berlin, no formal MMT was available until 1989. Since then MMT has been provided by general practitioners and includes regular medical and psychosocial counselling. It is required that IDUs attend counselling sessions. IDUs with serious health problems (such as HIV related diseases), and IDUs with long and severe injecting careers have better access to MMT in Germany than other IDUs. A range of additional AIDS prevention measures have been implemented in Berlin since 1985, including syringe exchange programmes, outreach work, and extended treatment facilities. There is a need to determine whether MMT has a role in reducing risk behaviour among IDUs in a community where IDUs have good access to sterile injection equipment.

From 1992-93, a multi-site cross sectional study on the epidemiology of HIV infection and viral hepatitis among IDUs was carried out. One objective of the study was to assess whether MMT is protective against HIV risk taking behaviour among IDUs in Berlin. Moreover, we wanted to investigate which behavioural characteristics among the IDUs were independent predictors of needle sharing, and could be specifically addressed by preventive activities.

\section{Methods}

The study participants were recruited from October 1992 to September 1993 at two "drug free" long term treatment centres, an infectious diseases hospital, two walk in agencies where 
counselling on HIV and drug abuse, syringe exchange, and basic medical care for IDUs is provided free of charge, and on the streets at main gathering places of IDUs. Individuals were eligible for participation in the study if they had injected drugs within the previous three months. Verbal informed consent was obtained from the participants and they were asked to answer anonymously a standardised questionnaire. From the IDUs recruited at the treatment centres, the walk in agencies, or the hospital a blood sample was obtained for HIV antibody testing. Street-recruited IDUs provided a saliva sample because it would not have been feasible to draw blood at these locations. Saliva testing for HIV antibodies has been shown to have high sensitivity and specificity. ${ }^{15}$ The study was approved by the data protection office and the ethics committee. The questionnaire covered sociodemographic characteristics, drug use paterns, drug treatment experience, and contained questions on injection and sexual behaviour for the time since starting injecting drug use and in particular detail for the six months before the interview. Risk taking behaviour during the six months before interview is referred to as recent risk behaviour. The questionnaire was administered by specifically trained interviewers. To reduce interviewer bias between sites, the same interviewers carried out interviews at different sites of recruitment.

Serum and saliva samples were tested for HIV antibodies by enzyme linked immunosorbent assay (HIV-1/2 ELISA, Sanofi Pasteur, Freiburg, Germany). Positive results were confirmed by western blotting (Sanofi Pasteur) according to WHO guidelines.

Overall, 659 IDUs were enrolled in the study. After exclusion of IDUs who had been interviewed twice $(n=39)$ by different interviewers, or who provided insufficient volumes of blood or saliva $(n=4)$, and of four IDUs who had given inconsistent responses, the data of 612 IDUs were analysed. Of these IDUs, 179 had been recruited from the treatment centres, 227 from the walk in agencies, 55 from the hospital, and 151 from the streets. The corresponding response rates were $90 \%$, $85 \%, 93 \%$, and $76 \%$, respectively.

\section{STATISTICAL ANALYSIS}

In univariate analysis, associations between MMT status, other sociodemographic and behavioural characteristics, and the outcome variables "recent borrowing of used syringes", "recent lending of used syringes", "number of IDU sex partners in the previous 6 months", and "irregular condom use with non-commercial sex partners" were assessed by $\chi^{2}$ test (SPSS). To allow for potential confounding effects, multivariate analysis (logistic regression) was performed (EGRET). The variable "methadone maintenance treatment (MMT) during the entire previous six months" was treated as the explanatory variable of main interest, and for each outcome variable the crude odds ratio (OR) was calculated. Of all IDUs, 61 had received MMT during the entire previous six months, and 527 IDUs had never received MMT. Twenty four individuals had started MMT within the previous six months. Since they did not differ from the group not in MMT with regard to the levels of borrowing and lending of syringes, condom use, or maximum frequency of injecting in the previous six months they were grouped together with IDUs not in treatment for statistical analysis. Variables which were associated with the exposure and the outcome variable in univariate analysis, or which were considered as potential confounders a priori (age, schooling, duration of injecting drug use) were added to the model. A variable was kept in the model if its inclusion significantly reduced the deviance $(\mathrm{p}<0.05)$. Possible interactions were also assessed in the logistic regression models. ${ }^{16}$

An analysis of the responses by the IDUs who had been repeatedly interviewed by different interviewers, and checks for any inconsistencies showed that the data appear have good reliability and validity. ${ }^{17}$

\section{Results}

Of the total study population $(n=612)$, two thirds were males. The median age was 29 years (interquartile range 26-33). Males were significantly older (median 30 years) than females (28 years) $(\mathrm{p}<0.01$, Mann-Whitney $U$ test). The median duration of injecting drug use was 8 years (interquartile range $4-14$ years) and did not differ in relation to gender.

Of all IDUs, $61(10 \%)$ had received MMT for at least six months before the interview. The median duration of their MMT was 16 months (interquartile range 9-28 months). Table 1 shows selected characteristics of the study population in relation to MMT status. IDUs who had received MMT during the previous six months were older, had injected for a longer time, were more likely to be HIVpositive, had injected less frequently in the previous six months, and were less likely to have used heroin in the previous six months.

Of the study participants, $41 \%(251 / 612)$ reported they had borrowed used syringes from other persons in the previous six months. Overall, $34 \%(208 / 612)$ of the IDUs had lent used syringes to other IDUs in the previous six months. Of the borrowers, $62 \%$ also had lent injection equipment (non-borrowers: 15\%), and of the lenders, $75 \%$ also had borrowed used equipment in the previous six months (non-lenders: $26 \%)(p<0.0001)$.

In univariate analysis, IDUs in MMT were less likely to have borrowed and to have passed on used syringes recently. For IDUs in MMT compared with IDUs not in MMT, the crude odds ratios (OR) with $95 \%$ confidence intervals (CI) for borrowing and for lending syringes were 0.25 (95\% CI $0.13,0.51)$, and $0.39(95 \%$ CI $0.17,0.89)$, respectively.

After adjusting for confounding effects in logistic regression, MMT remained protective against the borrowing of syringes (adjusted OR $0.36,95 \%$ CI $0.16,0.80$ ) (table 2) but not against the lending of syringes (adjusted OR $0.85,95 \%$ CI $0.32,2.3)$. Among the confounding factors for the association between 
Table 1 Selected characteristics of intravenous drug users (IDUs) in methadone maintenance treatment (MMT) and not in $M M T$

\begin{tabular}{|c|c|c|c|c|}
\hline \multirow[t]{2}{*}{ Variable } & \multirow[t]{2}{*}{ All IDUs (no) } & \multicolumn{2}{|c|}{ Frequency distribution of variable in $\%$} & \multirow[t]{2}{*}{ p value } \\
\hline & & $\begin{array}{l}\text { IDUs in } M M T \\
(n=61)\end{array}$ & $\begin{array}{l}\text { IDUs not in } M M T \\
(n=551)\end{array}$ & \\
\hline \multirow{4}{*}{$\begin{array}{l}\text { Male gender } \\
\text { Age (y): } \\
<25 \\
25-29 \\
\geq 30\end{array}$} & 412 & 67 & 67 & \multirow{4}{*}{$\begin{array}{l}\text { NS } \\
<0.001\end{array}$} \\
\hline & & & & \\
\hline & 110 & 2 & 20 & \\
\hline & $\begin{array}{l}205 \\
297\end{array}$ & 34 & 33 & \\
\hline \multicolumn{2}{|l|}{ Duration of injecting drug use $(y)$ : } & & 47 & \multirow[t]{4}{*}{$<0.0001$} \\
\hline$<5$ & 163 & 10 & 29 & \\
\hline $5-9$ & 174 & 15 & 30 & \\
\hline \multicolumn{2}{|l|}{ Result of previous HIV test (self reported): } & 75 & 42 & \\
\hline $\begin{array}{l}\text { Negative } \\
\text { Nelis (sel reportea): }\end{array}$ & 415 & 41 & 71 & \multirow{4}{*}{$<0.0001$} \\
\hline Positive & 95 & 51 & 12 & \\
\hline Result not known & 29 & 3 & 5 & \\
\hline Not tested & 73 & 5 & 13 & \\
\hline HIV seropositivity (laboratory test) & 107 & 51 & 14 & $<0.0001$ \\
\hline \multirow{2}{*}{\multicolumn{2}{|c|}{$\begin{array}{l}\text { Characteristics concerning the previous } 6 \text { months } \\
\text { Maximum frequency of injecting: }\end{array}$}} & & & \\
\hline & & & & \multirow[t]{2}{*}{$<0.0001$} \\
\hline Less than once a day & 149 & 67 & 20 & \\
\hline Use of heroin & 593 & 80 & 99 & $<0.0001$ \\
\hline Use of cocaine & 477 & 75 & 78 & NS \\
\hline Use of seditiva* & 459 & 74 & 75 & NS \\
\hline Borrowed used syringes & 251 & 16 & 44 & $<0.0001$ \\
\hline Passed on used syringes & 208 & 18 & 36 & $<0.005$ \\
\hline Injected drugs in prison & 60 & 3 & 11 & \multirow{5}{*}{$\begin{array}{l}0.07 \\
\text { NS }\end{array}$} \\
\hline \multirow{2}{*}{$\begin{array}{l}\text { No of IDU sex partners: } \\
\text { None }\end{array}$} & & & & \\
\hline & 312 & 54 & 51 & \\
\hline One & 224 & 39 & 36 & \\
\hline More than one & 76 & 7 & 13 & \\
\hline \multirow{4}{*}{$\begin{array}{l}\text { Condom uset: } \\
\text { Never } \\
\text { Sometimes } \\
\text { Always }\end{array}$} & & & & \multirow[t]{4}{*}{ NS } \\
\hline & 280 & 63 & 71 & \\
\hline & 51 & 11 & 13 & \\
\hline & 69 & 26 & 16 & \\
\hline
\end{tabular}

* Benzodiazepines and/or barbiturates.

† In sexual contact with non-commercial partners.

NS $=$ not significant.

MMT and the borrowing of syringes were behavioural characteristics which themselves have to be regarded as important independent predictors of the borrowing of syringes (table 2). IDUs who had injected drugs in prison in the previous six months, who had used sedatives, or who had had sex with another IDU in the previous six months were significantly more likely to have borrowed syringes during this time period. No interactions were found.

Of all IDUs, $72 \%$ (441/612) had had vaginal or anal sexual contacts in the previous six months, $52 \%$ had had sex with non-commercial partners only, $7 \%$ had had sex only in exchange for drugs or money, and $13 \%$ had had sex with both non-commercial and commercial partners. Of all IDUs, $49 \%$ had had sex with other IDUs. Only $17 \%$ of the sexually active IDUs reported to have always used condoms with non-commercial sex partners, $14 \%$ had sometimes, and $69 \%$ had never used condoms. When having sex with commercial partners, $85 \%$ of the IDUs reported to have always used condoms. The number of IDU sex partners

Table 2 Associations of behavioural characteristics and the borrowing of used syringes in the six months before the interview among intravenous drug users (IDUs) (logistic regression)

\begin{tabular}{llc}
\hline Variable & Adjusted odds ratio $(95 \%$ CI $)$ & $p$ value \\
\hline $\begin{array}{l}\text { Methadone maintenance } \\
\text { Yes }\end{array}$ & $0.36(0.16,0.80)$ & 0.02 \\
$\begin{array}{l}\text { Injected drugs in prison } \\
\quad \text { Yes }\end{array}$ & $4.82(2.55,9.11)$ & $<0.001$ \\
$\begin{array}{l}\text { Use of sedatives* } \\
\quad \text { Yes }\end{array}$ & $2.35(1.51,3.65)$ & $<0.001$ \\
$\begin{array}{l}\text { Sex with other IDUs } \\
\text { Yes }\end{array}$ & $2.23(1.55,3.21)$ & $<0.001$ \\
\hline
\end{tabular}

* Benzodiazepines and/or barbiturates.

The final logistic regression model included the variables in the table plus the confounding variables "duration of injecting drug use", "frequency of injecting", and "result of previous HIV testing”. and the levels of condom use in the previous six months did not differ significantly in relation to MMT status (table 1). The same was found in logistic regression analysis (data not shown).

\section{Discussion}

The study showed that MMT, if given under structured conditions, may be protective against the borrowing of syringes among IDUs in Berlin. After adjusting for confounding factors such as frequency of injecting, HIV serostatus, and injecting drug use in prison, IDUs who had received MMT throughout the entire six months before the interview were less than half as likely to have borrowed used syringes during this time period. This is the first study with multisite sampling of IDUs to show such an effect in Germany, where there has been a long standing debate on the benefits of MMT. Since our study included only IDUs who had injected at least once in the previous six months it probably underestimates the protective effect of MMT against the borrowing of syringes. The level of the borrowing of syringes among the IDUs in MMT in this study was lower than among clients of a "low threshold" MMT programme in Amsterdam. ${ }^{13}$ This indicates that it is not just the pharmacological effect of methadone itself but rather its combination with regular counselling and sociomedical support which is effective. In communities where IDUs have ready access to sterile injection equipment MMT may play an important role among the other prevention activities.

In our study, HIV positive individuals were over-represented among the IDUs receiving MMT compared with IDUs not in MMT. This is due to the fact that in Germany HIV infected 
IDUs have better access to MMT than HIV negative IDUs. In order to take advantage of the protective effects of MMT against the borrowing of syringes, the access to MMT should be improved for HIV negative IDUs.

It is noteworthy, however, that $16 \%$ of the study participants had borrowed used syringes in the previous six months despite receiving MMT. Moreover, after adjusting for confounding effects, IDUs in MMT were not significantly less likely to lend syringes. This is of particular concern because a high proportion of IDUs in MMT are HIV infected and may pass on the virus by lending their contaminated injection equipment to other IDUs. MMT did not have any effect on the number of sexual partners or on the levels of condom use in the previous six months. This is in accordance with results published previously indicating that it is difficult to modify the sexual risk behaviour of IDUs. ${ }^{418}$

The possibility has to be considered that our findings may in part be due to socially desirable responding. However, the data were obtained anonymously by trained external interviewers. The IDUs were recruited at different sites and institutions, but not directly at the centres providing MMT. Thus, IDUs in MMT did not have to fear any consequences if they reported that they frequently injected drugs or shared syringes despite receiving MMT. Thus, we believe that giving socially desirable responses cannot explain the results of the study.

The study identified several important behavioural characteristics which were associated with a significantly increased adjusted odds ratio for borrowing syringes. Injecting drug use in prison in the previous six months was a strong predictor of the recent borrowing of syringes. Inside prisons, sterile syringes are hardly available, and the relatively high levels of syringe sharing in prison settings are likely to result in ongoing transmission of HIV and hepatitis viruses. ${ }^{171920}$ This is seriously counteracting the successful prevention strategies implemented outside prisons in many communities. Prevention measures in prison could include the provision of sterile injection equipment in settings where it is feasible, or at least the provision of effective disinfectants.

IDUs who had used sedatives in the previous six months were also more likely to borrow syringes after adjusting for confounding effects by other variables such as MMT and frequency of injecting. This association remained after additionally adjusting for the number of drugs used, although the adjusted odds ratio for borrowing syringes among sedative users was somewhat reduced from 2.4 to 2.2 . We cannot entirely rule out undetected confounding. However, it seems plausible that the reduced levels of consciousness due to sedative use may result in a loss of risk awareness and thereby increase the levels of risk behaviour. Our results are in accordance with previous studies which also found increased levels of syringe sharing among benzodiazepine users. ${ }^{21}$ Efforts to reduce the use of sedatives among IDUs should include specific counselling programmes on the hazards of benzodiazepine and barbiturate use, and improve the access to specific facilities for treatment of sedative abuse.

Having had an IDU sex partner in the previous six months also increased the risk of borrowing syringes. This finding corroborates those of other studies. ${ }^{223}$ Since clients of MMT are in frequent contact with health professionals and social workers, such programmes would provide an excellent opportunity to repeatedly address the risks of sexual virus transmission among IDUs.

We are grateful to the staff of the agencies which participated in the study. The study was funded in part by the Bundesministerium für Forschung und Technologie (Berliner Forschungsverbund Public Health, grant: FKZ 07 PHF 01-B6).

1 Chaisson RE, Moss AR, Onishi R, Osmond D, Carlson JR. Human immuno-deficiency virus infection in heterosexual intravenous drug users in San Francisco. Am $\mathcal{f}$ Public Health 1987;77:169-72.

2 Novick DM, Trigg HL, Des Jarlais DC, Friedman SR, Vlahov D, Kreek MJ. Cocaine injection and ethnicity in parenteral drug users during the early years of the human immunodeficiency virus (HIV) epidemic in New York City. F Med Virol 1989;29:181-5.

3 Schoenbaum EE, Hartel D, Selwyn PA, et al. Risk factors for human immunodeficiency virus infection in intravenous drug users. $N$ Engl $₹$ Med 1989;321:874-9.

4 Des Jarlais DC, Friedman SR, Choopanya K, Vanichseni $\mathrm{S}$, Ward TP. International epidemiology of HIV and AIDS among injecting drug users. AIDS 1992;6:1053-68.

5 Donoghoe MC, Stimson GV, Dolan K, Aldritt L. Changes in HIV risk behaviour in clients of syringe-exchange schemes in England and Scotland. AIDS 1989;3:267-72.

6 Robert CF, Deglon JJ, Wintsch J, et al. Behavioural changes in intravenous drug users in Geneva: rise and fall of HIV infection, 1980-1989. AIDS 1990;4:657-60.

7 Ljungberg B, Christensson B, Tunving K, et al. HIV prevention among injecting drug users: three years of experience from a syringe exchange program in Sweden. $\mathcal{f}$ Acquir Immune Defic Syndr 1991;4:890-5.

8 Van Haastrecht HJA, Van den Hoek JAR, Bardoux C, Leentvar-Kuypers A, Coutinho RA. The course of the HIV epidemic among intravenous drug users in Amsterdam, The Netherlands. Am ₹ Public Health 1991;81: 59-62.

9 Stark K, Müller R. HIV prevalence and risk behaviour in injecting drug users in Berlin. Forensic Sci Int 1993;62: 73-8

10 Abdul-Quader AS, Friedman SR, Des Jarlais DC, Marmor MM, Maslansky R, Bartelme S. Methadone maintenance and behaviour by intravenous drug users that can transmit HIV. Contemporary Drug Problems 1987;14:425-34.

11 Ward J, Darke S, Hall W, Mattick R. Methadone maintenance and the human immunodeficiency virus: current issues in treatment and research. British fournal of Addiction 1992;87:447-53.

12 Kang SY, De Leon G. Correlates of drug injection behaviours among methadone outpatients. Am 7 Drug Alcohol Abuse 1993;19:107-18.

13 Hartgers C, Van den Hoek A, Krijnen P, Coutinho RA. HIV prevalence and risk behavior among injecting drug users who participate in "low-threshold" methadone programs in Amsterdam. Am $\mathcal{F}$ Public Health 1992;82:547-51.

14 Baker A, Kochan N, Dixon J, Wodak A, Heather N. HIV risk-taking behaviour among injecting drug users currently, previously and never enrolled in methadone treatment. Addiction 1995;90:545-54.

15 Stark K, Warnecke C, Brinkmann V, Gelderblom HR, Bienzle U, Pauli G. Sensitivity of HIV antibody detection in saliva. Med Microbiol Immunol 1993;182:147-51.

16 Kleinbaum DG, Kupper LL, Morgenstern H. Epidemiologic research. Principles and quantitative methods. New York: Van research. Principles and quantice
Nostrand Reinhold, 1982.

17 Müller R, Stark K, Guggenmoos-Holzmann I, Wirth D, Bienzle U. Imprisonment: a risk factor for HIV infection counteracting education and prevention programmes for intravenous drug users. AIDS 1995;9:183-90.

18 WHO Collaborative Study Group. An international comparative study of HIV prevalence and risk behaviour among drug injectors in 13 cities. Bull Narcotics 1993;45: $19-46$.

19 Gore SM, Bird AG, Burns SM, Goldberg DJ, Ross AJ, Macgregor J. Drug injection and HIV prevalence in inmates of Glenochil prison. BMF 1995;310:293-6.

20 Taylor A, Goldberg D, Emslie J, et al. Outbreak of HIV infection in a Scottish prison. BMF 1995;310:289-92.

21 Darke S, Ross J, Cohen J. The use of benzodiazepines among regular amphetamine users. Addiction 1994;89: 1683-90.

22 Booth RE. Predictors of unsafe needle practices: injection drug users in Denver. $\mathcal{F}$ Acquir Immune Defic Syndr 1994; 7:504-8.

23 Darke S, Swift W, Hall W, Ross M. Predictors of injecting and injecting risk-taking behaviour among methadone maintenance clients. Addiction 1994;89:311-6. 